\title{
Work-Family Conflict and Self-Rated Health: the Role of Gender and Educational Level. Baseline Data from the Brazilian Longitudinal Study of Adult Health (ELSA-Brasil)
}

\author{
Rosane Härter Griep ${ }^{1,2}$ (D) S Susanna Toivanen ${ }^{2} \cdot$ Cornelia van Diepen ${ }^{3} \cdot$

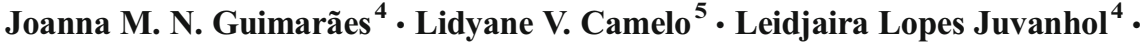 \\ Estela M. Aquino ${ }^{6}$ • Dóra Chor ${ }^{4}$
}

Published online: 23 November 2015

(C) The Author(s) 2015. This article is published with open access at Springerlink.com

\begin{abstract}
Purpose This study examined gender differences in the association between work-family conflict and self-rated health and evaluated the effect of educational attainment.

Method We used baseline data from ELSA-Brasil, a cohort study of civil servants from six Brazilian state capitals. Our samples included 12,017 active workers aged 34-72 years. Work-family conflict was measured by four indicators measuring effects of work on family, effects of family in work and lack of time for leisure and personal care.

Results Women experienced more frequent work-family conflict, but in both genders, increased work-family conflict directly correlated with poorer self-rated health. Women's educational level interacted with three work-family conflict indicators. For time-based effects of work on family, highly educated women had higher odds of suboptimal self-rated health
\end{abstract}

Rosane Härter Griep

rohgriep@gmail.com

1 Laboratory of Health and Environment Education, Oswaldo Cruz Institute, Oswaldo Cruz Foundation, Avenida Brasil, 4365, Manguinhos Rio de Janeiro 21040-360, Brazil

2 Centre for Health Equity Studies, Stockholm University and Karolinska Institutet, Stockholm, Sweden

3 Department of Geography, Portsmouth University, Portsmouth, UK

4 National School of Public Health, Oswaldo Cruz Foundation, Rio de Janeiro, Rio de Janeiro, Brazil

5 Postgraduate Program in Public Health, Faculty of Medicine, Universidade Federal de Minas Gerais, Minas Gerais, Brazil

6 Institute of Collective Health, Federal University of Bahia, Salvador, Bahia, Brazil
$(\mathrm{OR}=1.54 ; 95 \% \mathrm{CI}=1.19-1.99)$ than less educated women $(\mathrm{OR}=1.14 ; 95 \% \mathrm{CI}=0.92-1.42)$. For strain-based effects of work on family, women with higher and lower education levels had $\mathrm{OR}=1.91$ (95\% CI 1.48-2.47) and $\mathrm{OR}=1.40$ (95\% CI 1.12-1.75), respectively. For lack of time for leisure and personal care, women with higher and lower education levels had $\mathrm{OR}=2.60(95 \% \mathrm{CI}=1.95-3.47)$ and $\mathrm{OR}=1.11$ (95\% CI=0.90-1.38), respectively.

Conclusion Women's education level affects the relationship between work-family conflict and self-rated health. The results may contribute to prevention activities.

Keywords Gender · Work and family conflict · Self-rated health $\cdot$ Educational level $\cdot$ ELSA-Brasil cohort study

\section{Introduction}

With greater participation of women in the workforce over recent decades in most parts of the world, both men and women are involved in work and family life $[1,2]$. In Brazil, women have only relatively recently entered the labour market, but their contribution has grown rapidly. The proportion of women in the workforce increased from $32 \%$ in 1980 to $57 \%$ in 2009. The female-to-male labour force participation rate also increased from $52.2 \%$ in 1990 to $73.3 \%$ in 2010 and has continued to increase steadily $[3,4]$. This is good for the emancipation and economic independence of women but can also have its drawbacks as women and men now need to balance their responsibilities at home and work.

The division of household tasks and childcare responsibility between working men and women, however, has not undergone similar changes and is still unequal [5]. It also varies by country and region [6]. For example, in Sweden, a country 
with high gender equality, women carry out an average of $26 \mathrm{~h}$ of unpaid work each week, whereas men do about $21 \mathrm{~h}$ [7]. In Europe as a whole, women spend an average of $26 \mathrm{~h}$ per week on care and household activities, compared with $9 \mathrm{~h}$ for men (European Commission, Report on Progress on equality between women and men in 2013). In Brazil, the average unpaid work per week is $25 \mathrm{~h}$ for women and about $10 \mathrm{~h}$ for men [3]. Although men have slightly increased their participation in housework and childcare in Brazil, women still perform most family tasks and spend more time on unpaid domestic work even if they are in full-time paid work [1, 3, 8-11].

Balancing work and family demands is challenging, and one or other may require more time and attention than is available. The work-family conflict is defined as 'a form of interrole conflict in which the role pressures from the work and family domains are mutually incompatible in some respect' [12]. This imbalance is also conceptualized as work-life conflict or worklife imbalance $[13,14]$. Although correlated, work-family conflict and work-life conflict measures are, however, different [15]. The work-family conflict is more related to the lack of boundaries between work and family spheres and could be moderated by family status. Work-life imbalance research focuses on the spillover effect in a broader context, in which work influences experiences in the non-work sphere (for example, time for leisure, friends and family life) [15]. In the present study, we focused on work-family boundary management (rather than broader work-life issues) in two basic directions: work-tofamily or family-to-work conflict [16-22]. Most previous studies have focused on work-to-family conflict, viewed as resulting from occupational conditions [17, 19, 20, 22, 23]. Less often, family-to-work conflict has been investigated, and is viewed as arising from home and life circumstances [17-19, 24]. Some authors have postulated that family-to-work conflict could have more long-term consequences than work-to-family conflict [25, $26]$ and also have a greater influence on women's health [22, 26]. Other studies have also discussed work-to-family conflict as being more detrimental to women's health than to men's health [27, 28]. A few studies have described characteristics of work-family conflict as two distinguishable forms: time-based (time devoted to one role makes it difficult to participate in another) and strainbased (excessive effort to perform in one domain affects performance in the other) $[19,22]$. An additional form of conflict, behaviour-based work-family conflict, refers to specific behaviours in one role being incompatible with behaviours in the other $[17,19,21]$. However, little is known about gender-based antecedents or outcomes for each of these forms [17, 19, 22].

More recently, some authors have suggested that work and non-work are no longer separate domains and can simultaneously affect quality of life, leisure and health, with a different pattern according to gender [2, 18-20,24, 29]. Based on this literature, we included a measure in the present study of both domains (work and family) simultaneously affecting leisure time and self-care.
Previous studies have investigated the association between work-family conflict and health status, such as common symptoms, mental health or depression [16, 19, 30-32], and whether work-family conflict may reduce the well-being benefits of employment [19,33]. Some studies have also reported an association between work-family conflict and poorer selfrated health [16, 34-36]. Self-rated health expresses subjective as well as objective aspects of health and could reflect gender differences in stress response. It has been shown to be a predictor of future morbidity and mortality, functional decline and disability and higher utilization of health care [37-39].

Much of the literature shows that gender differences in work environment and family characteristics affect the association between work-family conflict and health [19, 27, 31, 34]. Gender is an essential determinant of inequalities in work-family conflict [36]. Most previous studies have distinguished between genders, and the results generally show a higher prevalence of work-family conflict and suboptimal self-rated health among women [36, 40, 41], although some studies found similar results in men and women [27, 32, 34].

Educational level also affects the experience of work-family conflict and the resulting mental health consequences [23, 42]. Individuals with higher educational attainment tend to express more work-family conflict. This might be due to high-pressure jobs and working longer hours than people with lower levels of education [23]. Educational level is also closely related to inequalities in health and is often used as a proxy for occupational prestige [23]. Groups with lower levels of education have a higher risk of mortality [43] and worse self-rated health than highly educated groups [44]. It is therefore possible that education level might modify the association between work-family conflict and self-rated health. To our knowledge, no previous studies have investigated this interaction considering gender stratification.

The association between work-family conflict and health status has been well-studied, mostly in western Europe and North America. In Brazil, the most populous country in South America, income and gender inequality remain high [3], but studies about influence of work-family conflict on health are scarce. This study therefore aims to investigate gender differences in the association between work-family conflict and selfrated health, and to evaluate whether educational attainment modifies this association, using data from the baseline of the Brazilian Longitudinal Study of Adult Health (ELSA-Brasil).

\section{Methods}

\section{Study Design}

The ELSA-Brasil design and concepts have been detailed elsewhere [45]. The study population consisted of 15,105 civil servants ( $46 \%$ men, with ages ranging from 34 to 75 years). 
The ELSA-Brasil cohort comprised voluntary participants. Effort was made to recruit similar proportions of both genders, as well as predefined proportions of specific age groups and distinct occupational categories, to permit a wide socioeconomic gradient across the sample. Participants were recruited from five universities and one research institute in six Brazilian state capitals (Federal Universities of Bahia, Espírito Santo, Minas Gerais, and Rio Grande do Sul, the University of São Paulo, and the Oswaldo Cruz Foundation).

Baseline assessment (2008-2010) included comprehensive questionnaire interviews conducted by trained personnel and clinical and laboratory measurements [45-47]. The population in our study included only active workers $(n=12,096)$ and missing values on these central variables were excluded $(n=$ 79). This resulted in a sample of 12,017 valid subjects $(99.3 \%)$ for analysis.

\section{Self-Rated Health}

Self-rated health was evaluated by a single question: In general, compared with other people your age, how would you rate your health? The respondents answered on a five-point scale, later dichotomized into 'good' (good and very good) and 'suboptimal' (fair, poor and very poor).

\section{Work-Family Conflict}

Four indicators of work-family conflict were measured. The three first items were based on the model designed by Frone and colleagues [16, 25], and the psychometric properties have been previously shown [48]. The first statement, assessing time-based work-to-family conflict, stated: Demands (requirements or requests) from work keep you from spending the amount of time you would like with your family (kappa $=0.63$; confidence interval [CI] 0.52-0.71). The second statement, assessing strain-based work-to-family conflict, stated: Demands (requirements or requests) from work make it difficult to fulfil domestic responsibilities, such as caring for the house and children (kappa $=0.56$; CI 0.45-0.67). The third statement, assessing family-to-work conflict, stated: Demands (requirements or requests) from your family interfere with your responsibilities at work, such as getting to work on time, accomplishing daily tasks, travelling for work, and attending meetings outside the regular work schedule (kappa $=0.46$; CI $0.32-0.58)$. The fourth statement was designed by ELSABrasil researchers to cover the simultaneous effects of both work and family on lack of time for leisure and self-care [29]: Demands (requirements or requests) from your family and work keep you from spending the amount of time you would like on your own care and leisure activities (kappa= 0.70 ; CI 0.63-0.77). Each statement used a five-point frequency-based response scale: never to almost never, rarely, sometimes, frequently and very frequently. The categories were grouped into three levels: 1 was 'never to rarely' (reference category), 2 was 'sometimes' and 3 'frequently'.

\section{Covariates}

The covariates examined were the following: age (continuous); education ('lower' lower than complete university degree or 'higher' complete university degree or above); marital status (married or living together; divorced, separated or widowed; or single living without partner); the presence of children under the age of five in the household (yes/no); the presence of a maid in the household (yes/no); hours worked per week (continuous); shift work (daytime employment without weekends, dayshifts which included weekends, and mostly nightshifts or mixed shifts); and self-reported medical diagnosis of chronic diseases (if respondents reported at least one of the following diseases, they were coded as 'yes', otherwise 'no' hypertension, diabetes, myocardial infarction, stroke and heart failure).

\section{Statistical Analyses}

We performed all analyses separately for women and men. Chi-squared and $t$ tests were used for descriptive analyses of covariates and work-family conflict. All covariates associated with the outcome $(p \leq 0.05)$ were included in multiple logistic regression analysis to estimate odds ratios (OR) and $95 \% \mathrm{CI}$. The collinearity between the covariates was tested by generalized variance inflation factor (GVIF) [49]. Because of the risk of over-adjusting the four areas of work-family conflict, all covariates were tested individually to determine their effect on the association between each area of work-family conflict and self-rated health. To evaluate the importance of each variable in the model, we used deviance statistics and the Akaike information criterion (AIC). Lower values were considered a better fit.

Multiplicative interaction between work-family conflict indicators and education was assessed by the inclusion of an interaction term in the full adjusted regression models (workfamily conflict*education). When the interaction term was significant $(p<0.1)$, the OR was estimated again with the effect of the interaction between the work-family conflict indicator and education [50].

All analyses were conducted in SPSS 22.0 for Windows and free software R, version 3.1.2 (R Development Core Team, Vienna, Austria).

\section{Results}

The mean age was similar for men and women. Women generally had higher levels of education; they were more likely to be divorced, separated, widowed or single, worked fewer 
hours per week and more often in day shifts. The frequency of self-reported chronic diseases was lower among women. Similar proportions of men and women reported having children under 5 years of age and having a maid (Table 1). Over $90 \%$ of women vs $70 \%$ of men worked in non-manual jobs. The occupational nature of a participant's present job (classified into four levels: routine/manual; non-routine/manual; routine/non-manual; and non-routine/non-manual) were strongly correlated with educational level for both women and men (Spearman's correlation coefficient 0.68 and 0.76 , respectively, $p<0.001$ ) (data not shown).

The overall prevalence of suboptimal self-rated health was $18.7 \%$ and comparable in men and women (18.7 and $18.4 \%$, respectively; $p=0.72$ ). Men and women who reported suboptimal health were older, had lower educational levels and worked fewer hours per week than those with good self-rated health.
Higher levels of suboptimal health were observed in divorced, separated or widowed respondents, those who had no maid and those who reported chronic diseases. Type of work shift and presence of children under 5 years of age were not associated with higher levels of suboptimal health $(p>0.05)$ (Table 1).

In general, women reported frequent work-family conflicts more often than men. For both genders, participants with higher education reported work-family conflict more often. An exception was observed for family-to-work conflict, which was similar for both genders with those with lower education commonly reporting more frequent conflict. In men, frequent family-towork conflict was associated with a higher level of suboptimal health $(p<0.001)$. For women, the same tendency was observed for three out of four work-family conflict indicators: work-tofamily strain-based, family-to-work conflict and lack of time for leisure and personal care (Table 2).

Table 1 Prevalence of suboptimal self-rated health among men and women, by covariables, ELSA-Brasil baseline $(2008-10 ; n=12,017)$

\begin{tabular}{|c|c|c|c|c|}
\hline & \multicolumn{2}{|c|}{$\operatorname{Men}(n=5735)$} & \multicolumn{2}{|c|}{ Women $(n=6282)$} \\
\hline & All & $\begin{array}{l}\text { Suboptimal health } \\
(n=1070)\end{array}$ & All & $\begin{array}{l}\text { Suboptimal health } \\
(n=1156)\end{array}$ \\
\hline Age, mean (SD) & $49.5(7.4)$ & $51.1(6.9)^{* * *}$ & $48.9(7.1)$ & $50.1(7.0)^{* * *}$ \\
\hline \multicolumn{5}{|l|}{ Educational level (\%) } \\
\hline University degree & 49.6 & $12.3^{* * *}$ & 55.6 & $12.1 * * *$ \\
\hline Complete high school & 35.4 & 20.1 & 37.2 & 24.0 \\
\hline Complete elementary school & 7.9 & 30.6 & 4.5 & 35.8 \\
\hline Never attender or incomplete elementary school & 7.1 & 45.3 & 2.8 & 45.2 \\
\hline \multicolumn{5}{|l|}{ Marital status (\%) } \\
\hline Married/living together & 81.1 & $19.0^{* *}$ & 55.1 & $17.6^{* * *}$ \\
\hline Divorced/separated/widowers & 13.4 & 19.4 & 30.8 & 21.3 \\
\hline Single & 5.6 & 14.4 & 14.1 & 15.1 \\
\hline \multicolumn{5}{|l|}{ Children under 5 years } \\
\hline Yes & 13.2 & 17.5 & 10.0 & 20.0 \\
\hline No & 86.8 & 18.8 & 90.0 & 18.2 \\
\hline \multicolumn{5}{|l|}{ Presence of a maid } \\
\hline Yes & 22.2 & $13.6^{* * *}$ & 25.5 & $12.3 * * *$ \\
\hline No & 77.8 & 20.1 & 74.5 & 20.5 \\
\hline \multicolumn{5}{|l|}{ Working hours } \\
\hline$<39$ & 12.8 & $25.4 * * *$ & 22.3 & $24.4 * * *$ \\
\hline 40 to 59 & 72.0 & 18.4 & 67.8 & 16.9 \\
\hline$\geq 60$ & 15.2 & 14.4 & 9.9 & 14.8 \\
\hline \multicolumn{5}{|l|}{ Type of shift work (\%) } \\
\hline Daytime & 65.9 & 18.7 & 65.6 & 18.4 \\
\hline Daytime shifts & 12.5 & 17.6 & 17.3 & 17.3 \\
\hline Mixed or nightshifts & 21.6 & 19.8 & 17.1 & 19.9 \\
\hline \multicolumn{5}{|l|}{ Presence of self-reported chronic diseases ${ }^{\mathrm{a}}$} \\
\hline Yes & 36.4 & $32.4 * * *$ & 30.9 & $31.7 * * *$ \\
\hline No & 63.6 & 10.8 & 69.1 & 12.5 \\
\hline
\end{tabular}

*significant at $p \leq 0.05 ; * *$ significant at $p \leq 0.005 ; * * *$ significant at $p \leq 0.001$ in chi-square test or $\mathrm{t}$ test

${ }^{a}$ The self-reported chronic diseases used in this analysis are the following: hypertension, diabetes, myocardial infarction, stroke and heart failure 
Table 2 Work-family conflict indicators by education level and prevalence of suboptimal self-rated health among men and women; ELSA-Brasil baseline $(2008-10 ; n=12,017)$

\begin{tabular}{|c|c|c|c|c|c|c|c|c|}
\hline & \multicolumn{4}{|c|}{$\operatorname{Men}(n=5735)$} & \multicolumn{4}{|c|}{ Women $(n=6282)$} \\
\hline & All & $\begin{array}{l}\text { Low educated } \\
(n=2888)\end{array}$ & $\begin{array}{l}\text { High educated } \\
(n=2847)\end{array}$ & $\begin{array}{l}\text { Suboptimal } \\
\text { health }(n=1070)\end{array}$ & All & $\begin{array}{l}\text { Low educated } \\
(n=2788)\end{array}$ & $\begin{array}{l}\text { High educated } \\
(3494)\end{array}$ & $\begin{array}{l}\text { Suboptimal } \\
\text { health }(n=1156)\end{array}$ \\
\hline \multicolumn{9}{|c|}{ Work-to-family time-based } \\
\hline Never to rarely & 41.8 & 48.1 & $35.4^{* * *}$ & 19.3 & 39.8 & 47.8 & $33.3^{* * *}$ & 18.9 \\
\hline Sometimes & 32.3 & 31.4 & 33.2 & 17.8 & 28.2 & 26.4 & 29.7 & 17.4 \\
\hline Frequently & 25.9 & 20.5 & 31.4 & 18.7 & 32.0 & 25.8 & 36.9 & 18.6 \\
\hline \multicolumn{9}{|c|}{ Work-to-family strain-based } \\
\hline Never to rarely & 54.3 & 61.2 & $47.3^{* * *}$ & 18.4 & 45.4 & 53.9 & $38.7 * * *$ & $17.9^{* * *}$ \\
\hline Sometimes & 29.7 & 26.4 & 33.2 & 17.9 & 29.6 & 25.6 & 32.8 & 16.8 \\
\hline Frequently & 16.0 & 12.5 & 19.5 & 21.1 & 25.0 & 20.5 & 28.5 & 21.2 \\
\hline \multicolumn{9}{|l|}{ Family-to-work } \\
\hline Never to rarely & 67.0 & 70.2 & $63.8^{* * *}$ & $17.4^{* * *}$ & 68.6 & 70.2 & $65.5^{* * *}$ & $17.6^{* *}$ \\
\hline Sometimes & 25.5 & 21.0 & 30.1 & 19.4 & 25.5 & 22.4 & 28.2 & 19.0 \\
\hline Frequently & 7.5 & 8.8 & 6.1 & 27.0 & 6.8 & 7.4 & 6.4 & 23.8 \\
\hline \multicolumn{9}{|c|}{ Lack of time for leisure and personal care } \\
\hline Never to rarely & 44.2 & 54.2 & $34.0^{* * *}$ & 18.4 & 32.9 & 42.5 & $25.3^{* * *}$ & $19.3^{* * *}$ \\
\hline Sometimes & 32.0 & 30.2 & 33.8 & 18.3 & 32.6 & 30.0 & 34.7 & 15.6 \\
\hline Frequently & 23.8 & 15.6 & 32.1 & 19.7 & 34.5 & 27.5 & 40.1 & 20.2 \\
\hline
\end{tabular}

*significant at $p \leq 0.05 ; * *$ significant at $\leq 0.005 ; * * *$ significant at $p \leq 0.001$ in chi-square test

In men, the crude analyses showed frequent family-towork conflict was associated with greater odds of suboptimal self-reported health (OR 1.75; $95 \%$ CI 1.39-2.20; Table 3). After adjustment for covariates, all work-family conflict indicators were associated with suboptimal self-rated health, in a dose-response gradient. This gradient was statistically significant in the case of the family-to-work and lack of time for leisure and personal care indicators. Higher frequency of conflicts in those domains gave increased chances of suboptimal self-reported health. Adjustment by age and education had a mild effect on the association. Working hours and presence of disease showed the highest influence on the association (Table 3). The interaction terms by chi-square test indicated no influence of educational level on the association between work-family conflict indicators and suboptimal self-rated health among men $(p>0.10)$.

Higher odds of suboptimal self-reported health in crude analyses were observed for women who reported frequent work-to-family strain-based $(\mathrm{OR}=1.24 ; 95 \% \mathrm{CI}=1.06-1.44)$ or family-to-work $(\mathrm{OR}=1.46 ; 95 \% \mathrm{CI}=1.16-1.85)$ conflict (Table 4). Like men, after adjustment for covariates, women with frequent work-family conflict, as measured by all indicators had greater odds of suboptimal self-reported health, and we also observed a dose-response gradient except in lack of time for leisure and personal care. Adjustment for education showed the highest influence on the association between work-family conflict and suboptimal self-rated health (Table 4, Model 3). In fact, educational level interacted with three out of four workfamily conflict indicators among women (time-based work-tofamily conflict $p=0.08$; strain-based work-to-family conflict $p=$ 0.07; and lack of time for leisure and personal care $p<0.001$ ), but there was no evidence of interaction among women for family-to-work conflict $(p=0.26)$.

Table 5 shows the fully adjusted regression models, including a multiplicative interaction term for women. The results show that the association between frequent work-family conflict and suboptimal self-reported health was stronger in women with higher levels of education. For work-to-family timebased conflict, women with higher levels of education had higher odds for suboptimal self-related health $(\mathrm{OR}=1.54$; $95 \% \mathrm{CI}=1.19-1.99)$ than less educated women $(\mathrm{OR}=1.14$; $95 \% \mathrm{CI}=0.92-1.42$ ). Similarly, for work-to-family strainbased conflict, women with higher and lower levels of education had $\mathrm{OR}=1.91(95 \% \mathrm{CI}=1.48-2.47)$ and $\mathrm{OR}=1.40(95 \%$ $\mathrm{CI}=1.12-1.75)$. For lack of time for leisure and personal care, women with higher and lower educational levels had $\mathrm{OR}=$ $2.60(95 \% \mathrm{CI}=1.95-3.47)$ and $\mathrm{OR}=1.11(95 \% \mathrm{CI}=0.90$ $1.38)$.

\section{Discussion}

Our findings showed that women had a higher prevalence of work-family conflict and lack of time for leisure and personal 
Table 3 Crude and adjusted odds ratios of the association between work-family conflict indicators and suboptimal self-rated health among men, ELSA-Brasil, baseline (2008-10)

\begin{tabular}{|c|c|c|c|c|c|}
\hline \multirow[t]{2}{*}{ Work-family conflict indicators } & \multicolumn{5}{|l|}{ OR (CI 95\%) } \\
\hline & Model 1 & Model 2 & Model 3 & Model 4 & Model 5 \\
\hline \multicolumn{6}{|l|}{ Work to family time-based } \\
\hline Never to rarely & 1.00 & 1.00 & 1.00 & 1.00 & 1.00 \\
\hline Sometimes & $0.91(0.78-1.06)$ & $0.91(0.78-1.07)$ & $0.98(0.84-1.15)$ & $1.03(0.88-1.21)$ & $1.07(0.90-1.26)$ \\
\hline Frequently & $0.96(0.82-1.14)$ & $0.97(0.82-1.14)$ & $1.14(0.96-1.35)$ & $1.28(1.07-1.53)$ & $1.36(1.13-1.64)$ \\
\hline$A I C$ & 5524.1 & 5468.4 & 5305.8 & 5289.9 & 4989.0 \\
\hline \multicolumn{6}{|l|}{ Work to family strain-based } \\
\hline Never to rarely & 1.00 & 1.00 & 1.00 & 1.00 & 1.00 \\
\hline Sometimes & $0.97(0.83-1.13)$ & $0.98(0.84-1.15)$ & $1.10(0.94-1.29)$ & $1.15(0.98-1.35)$ & $1.18(1.00-1.39)$ \\
\hline Frequently & $1.19(0.99-1.42)$ & $1.21(1.01-1.46)$ & $1.43(1.19-1.73)$ & $1.62(1.33-1.97)$ & $1.67(1.36-2.05)$ \\
\hline$A I C$ & 5521.3 & 5464.9 & 5295.3 & 5275.5 & 4975.9 \\
\hline \multicolumn{6}{|l|}{ Family to work } \\
\hline Never to rarely & 1.00 & 1.00 & 1.00 & 1.00 & 1.00 \\
\hline Sometimes & $1.14(0.98-1.33)$ & $1.18(1.01-1.38)$ & $1.31(1.12-1.54)$ & $1.33(1.13-1.56)$ & $1.34(1.14-1.58)$ \\
\hline Frequently & $1.75(1.39-2.20)$ & $1.75(1.39-2.20)$ & $1.66(1.31-2.10)$ & $1.70(1.35-2.16)$ & $1.82(1.42-2.32)$ \\
\hline$A I C$ & 5503.3 & 5447.1 & 5284.9 & 5271.7 & 4971.0 \\
\hline \multicolumn{6}{|c|}{ Lack of time for leisure and personal care } \\
\hline Never to rarely & 1.00 & 1.00 & 1.00 & 1.00 & 1.00 \\
\hline Sometimes & $0.99(0.85-1.16)$ & $1.03(0.88-1.21)$ & $1.18(1.01-1.39)$ & $1.23(1.05-1.44)$ & $1.25(1.06-1.47)$ \\
\hline Frequently & $1.09(0.92-1.29)$ & $1.14(0.97-1.35)$ & $1.53(1.28-1.82)$ & $1.71(1.42-2.05)$ & $1.77(1.47-2.14)$ \\
\hline$A I C$ & 5524.3 & 5467.3 & 5287.2 & 5265.3 & 4965.1 \\
\hline
\end{tabular}

Model 1: unadjusted. Model 2: adjusted by age, model 3: Model 2+educational level; Model 4: Model 3+working hours; Model 5: Model 4+ presence of self-reported chronic diseases

care than men. Work-family conflict, as measured by the four indicators, was associated with higher odds of suboptimal health in both genders. The association differs by educational level only among women. More educated women with frequent work-family conflict in the work-to-family time-based, work-to-family strain-based and lack of time for leisure and personal care indicators had the highest odds of suboptimal health compared with women with lower levels of education.

\section{Findings Compared with Other Studies}

The women in our study reported fewer hours worked per week, but more frequent work-to-family conflict (both timeand strain-based) and lack of time for leisure and personal care than men. Although men generally spent more hours in paid work and on commuting than women, women tended to have less time available for leisure and personal care, because they spent more time on unpaid duties [51].

Women in our study were also more educated and more likely to be separated, widowed or single than men, which might indicate why they are in the labour market, and also that they could have less social support at home than men. Higher prevalence of work-family conflict among women has also been reported in previous studies [32, 34, 36, 52]. Research shows that the ability to balance work and private life remains problematic, especially for women [36]. Previous studies found that women's well-being is positively associated with time spent on paid work, and negatively associated with time spent taking care of home duties [11,53]. Women generally still have more responsibility for household duties, childcare and caring for older relatives, even in countries with gender mainstreaming and family-friendly policies. In a study among Swedish workers [40], multiple demands from work and private life increased the risk of fatigue in both genders, but only women reported that they wanted to reduce their working hours owing to the burden of managing multiple social roles. For cultural reasons, women may feel compelled to direct their energy and time towards the family and men may believe that their primary goal should be to maintain their position at work [40]. When the demands of work and home are combined, women have more responsibilities and work longer hours than men, and consequently experience stress more often $[11,51]$.

Despite more frequent work-to-family conflict among women, the association between work-family conflict and suboptimal self-rated health was observed in both genders. 
Table 4 Crude and adjusted odds ratios of the association between work-family conflict indicators and suboptimal self-rated health among women, ELSA-Brasil, baseline (2008-10)

\begin{tabular}{|c|c|c|c|c|c|c|}
\hline \multirow[t]{2}{*}{ Work-family conflict indicators } & \multicolumn{6}{|l|}{ OR (CI 95\%) } \\
\hline & Model 1 & Model 2 & Model 3 & Model 4 & Model 5 & Model 6 \\
\hline \multicolumn{7}{|l|}{ Work to family time-based } \\
\hline Never to rarely & 1.00 & 1.00 & 1.00 & 1.00 & 1.00 & 1.00 \\
\hline Sometimes & $0.90(0.77-1.06)$ & $0.91(0.78-1.07)$ & $1.02(0.87-1.21)$ & $1.03(0.88-1.21)$ & $1.06(0.90-1.25)$ & $1.10(0.93-1.30)$ \\
\hline Frequently & $0.98(0.84-1.14)$ & $0.98(0.85-1.14)$ & $1.18(1.01-1.38)$ & $1.21(1.03-1.41)$ & $1.29(1.09-1.51)$ & $1.30(1.10-1.53)$ \\
\hline AIC & 6002.8 & 5964.6 & 5757.3 & 5749.0 & 5743.6 & 5532.8 \\
\hline \multicolumn{7}{|l|}{ Work to family strain-based } \\
\hline Never to rarely & 1.00 & 1.00 & 1.00 & 1.00 & 1.00 & 1.00 \\
\hline Sometimes & $0.92(0.79-1.08)$ & $0.95(0.81-1.11)$ & $1.10(0.94-1.29) 1.11(0.94-1.30)$ & $1.14(0.97-1.34)$ & $1.15(0.98-1.35)$ & \\
\hline Frequently & $1.24(1.06-1.44)$ & $1.27(1.09-1.48)$ & $1.51(1.29-1.78)$ & $1.54(1.31-1.80)$ & $1.63(1.38-1.92)$ & $1.62(1.37-1.92)$ \\
\hline AIC & 5992.6 & 5953.3 & 5736.2 & 5727.3 & 5719.5 & 5511.1 \\
\hline \multicolumn{7}{|l|}{ Family to work } \\
\hline Never to rarely & 1.00 & 1.00 & 1.00 & 1.00 & 1.00 & 1.00 \\
\hline Sometimes & $1.10(0.95-1.27)$ & $1.13(0.97-1.31)$ & $1.22(1.05-1.42)$ & $1.23(1.06-1.44)$ & $1.24(1.06-1.44)$ & $1.23(1.05-1.44)$ \\
\hline Frequently & $1.46(1.16-1.85)$ & $1.48(1.17-1.87)$ & $1.46(1.15-1.86)$ & $1.47(1.16-1.88)$ & $1.47(1.16-1.88)$ & $1.53(1.19-1.96)$ \\
\hline AIC & 5994.5 & 5954.9 & 5748.9 & 5740.6 & 5738.7 & 5527.3 \\
\hline \multicolumn{7}{|l|}{ Lack of leisure time and personal care } \\
\hline Never to rarely & 1.00 & 1.00 & 1.00 & 1.00 & 1.00 & 1.00 \\
\hline Sometimes & $0.77(0.65-0.90)$ & $0.79(0.67-0.93)$ & $0.92(0.78-1.09) 0.94(0.79-1.11)$ & $0.95(0.81-1.13)$ & $0.98(0.83-1.16)$ & \\
\hline Frequently & $1.05(0.91-1.23)$ & $1.10(0.95-1.29)$ & $1.39(1.18-1.62)$ & $1.42(1.21-1.67)$ & $1.49(1.27-1.76)$ & $1.55(1.31-1.83)$ \\
\hline$A I C$ & 5987.5 & 5948.4 & 5734.8 & 5724.8 & 5718.3 & 5506.1 \\
\hline
\end{tabular}

Model 1: unadjusted. Model 2: adjusted by age, model 3: Model 2+educational level; Model 4: Model 3+ presence of maid; Model 5: Model 4+working hours; Model 6: Model 5+Presence of self-reported chronic diseases

Similar results have been found in other studies of different populations $[31,32,34,36]$. As more women participate in the workforce, both men and women need to operate in both work and family domains and to balance the demands of the two in a limited amount of time. Balancing the demands of work and family in modern life is a source of stress in adulthood and could influence the ranking of priorities for women and men and also reduce the time available for themselves, which can affect health and well-being $[18,29]$.
Table 5 Full adjusted logistic regression models of the association between work-family conflict indicators and suboptimal self-rated health including multiplicative interaction term (WFC*educational level) among women

\begin{tabular}{lll}
\hline Work-family conflict indicators & \multicolumn{2}{l}{ OR $(\mathrm{CI} 95 \%)^{\mathrm{a}}$} \\
\cline { 2 - 3 } & Low educated $(N=2788)$ & High educated $(N=3494)$ \\
\hline Work to family time-based & 1.00 & 1.00 \\
$\quad$ Never to rarely & $1.11(0.90-1.37)$ & $1.12(0.85-1.47)$ \\
Sometimes & $1.14(0.92-1.42)$ & $1.54(1.19-1.99)$ \\
Frequently & & 1.00 \\
Work to family strain-based & 1.00 & $1.13(0.87-1.47)$ \\
Never to rarely & $1.19(0.96-1.47)$ & $1.91(1.48-2.47)$ \\
Sometimes & $1.40(1.12-1.75)$ & \\
$\quad$ Frequently & & 1.00 \\
Lack of leisure time and personal care & 1.00 & $1.27(0.93-1.74)$ \\
Never to rarely & $0.92(0.75-1.14)$ & $2.60(1.95-3.47)$ \\
Sometimes & $1.11(0.90-1.38)$ & \\
Frequently & &
\end{tabular}

ELSA-Brasil baseline, 2008-10

${ }^{\text {a } A d j u s t e d ~ b y ~ a g e, ~ e d u c a t i o n a l ~ l e v e l, ~ p r e s e n c e ~ o f ~ m a i d, ~ w o r k i n g ~ h o u r s ~ a n d ~ p r e s e n c e ~ o f ~ s e l f-r e p o r t e d ~ c h r o n i c ~}$ diseases 
Some researchers have pointed out the relevance of distinguishing the direction of the conflict; in other words, whether family life interferes with work or vice versa. This increases understanding of the aspects influencing the workfamily conflict, and their health consequences [34, 54]. In line with previous findings, our results suggest both work-tofamily and family-to-work conflicts affected self-rated health among men and women [34].

Self-rated health is a multidimensional indicator that can reflect not only physical health, but also state of mind [55]. It is possible that work-family conflicts affect both physical and mental health through the stress cascade. Chronic exposure to stress increases the activities of physiological systems causing 'wear and tear', referred to as allostatic load, which is associated with stress hormones protecting the body through shortterm adaptation. In the long run, however, this causes mental and physical alterations that increase the risk of disease. Exposure to stress can also affect health indirectly by inducing a profile of adverse behaviours, such as smoking, sedentary habits, unhealthy diet and alcohol consumption [56]. Further research is necessary to determine which mechanisms cause the association between work-family conflict and health outcomes.

\section{Self-Rated Health and Educational Level}

We found that work-family conflict was more strongly associated with suboptimal self-rated health in more highly educated women, suggesting that education modifies the association between work-family conflict and self-rated health. This modification effect was not observed in men. Those in higher status occupations are more likely to have high-pressure jobs, flexible working hours and more responsibilities at work [31, 42], and all these characteristics are related to work-family conflict [23]. Workers in routine jobs, however, probably have greater segmentation of work and family roles, and they are more likely to know when work begins and ends, so they can experience lower permeability and flexibility between work and private life [42]. It is also possible that in the work environment of universities and research institutions, women with higher levels of education have jobs with high control and high demands, as well as a high competitive edge and expectations. They may also have extensive working hours with the boundaries between work and private life less clearly defined [57]. The balance between work and personal life reflects changes in the nature of work and workplaces related to general competition and trends [58]. The academic environment is increasingly investing in information technology to improve knowledge creation and distribution. Researchers and teachers are often asked to perform tasks in very short time periods, and as a consequence, work pressure increasingly spills over into their personal life [57, 59]. This situation could be even more critical among women, who generally have less autonomy to manage their time for self-care because they are often more involved with household tasks than men $[3,57]$. Previous studies also identified that the combination of high-powered job and family demands appears more challenging for women than men in higher white-collar occupations [27] or with higher educational levels [23]. All these elements could explain our findings that education modified the association between work-family conflict and self-reported health in women, but not men.

Research into work-life balance has mainly been with white-collar populations. The situation may, however, look different among blue-collar workers and those with lower levels of education [42]. As this study shows, work-family conflicts differ among women with lower and higher levels of education. This is an important finding showing that the social determinants are expressed differently in women with different levels of education.

Some specifics of the Brazilian culture might have influenced the results. It is difficult to determine if there is a discourse on work-family conflict in Brazil, which has a long history of gender inequality. If so, it is possible that this discourse has been more assimilated by women with higher levels of education. Lewis et al. [58] stated that the discourse is mostly present in western societies and that 'developing' countries have such different cultures that work-family conflict might be present but is difficult to uncover. The continuation of ELSA-Brasil with its longitudinal design, and other cohort studies, would give more insight in the directionality.

\section{Strengths and Weaknesses of the Study}

The main strength of this study is that it is based on detailed data collected from a large sample of current workers as part of the ELSA-Brasil cohort study. The data provided is an excellent opportunity to study work-family conflict in a middle income country where this issue has hardly been investigated. To the best of our knowledge, this is the first large-scale study examining work-family conflict in relation to selfreported health in Brazil. Besides, this study included one indicator that has not been used in work-family conflict research before. This indicator considered the influence of both domains simultaneously (work and family) on lack of time for leisure and personal care. This can be seen as an additional strength because this indicator presents new information about important aspects of modern life and may cast new light on studies of work-family conflict [29]. Our study highlights the importance of examining the interaction effect of educational level and the direction of work-to-family and family-to-work conflict, as well as the effect of both conflicts simultaneously in separate scales. We also investigated the influence of workto-family conflict by time-based and strain-based conflicts, which have not been the focus of many previous investigations [21, 22]. The behaviour-based conflict was not included in our study; according to some authors [17] few studies have 
investigated this dimension, and the meaning of behaviourbased conflict needs to be clarified.

Nevertheless, the study also has some limitations. This is a cross-sectional analysis, and temporality cannot be established. The temporal direction of the association is therefore less clear, and the associations may be bidirectional or resulting from common causes. ELSA-Brasil comprises a particular population (civil servants), so it may not be possible to generalize the results. However, the results may reflect the broader population in the same situation, for example, middle class-employed individuals or general civil servants who live in the larger metropolitan areas in Brazil. Moreover, given the nature of our sample, we did not have a substantial variation in terms of job levels, which may be considered a further limitation [60]. Our sample was homogeneous in terms of job tenure, and all participants were salaried employees from the public sector. Even so, our study sample had enough socioeconomic variability to capture gender differences in work-family conflict and the relationship with self-rated health across levels of education.

Although there is extensive research about work-family conflict, there is no consensus on the best way to measure this construct [17]. The literature describes different instruments and high variability in the number of dimensions and items, content, and presence of directionality of conflict $[17,27,31,32,36,40,60]$. It is possible that the workfamily conflict indicators used in this paper only partly represent the whole work-life conflict model because isolated items were used to measure complex dimensions of a higher construct; this is an important limitation of our study. It is, however, an important strength of our study that the work-family conflict indicators are not combined. Including different pathways in a single question, or combining pathways would make it difficult to understand the effect of the work-family conflict indicators on self-rated health. The indicators each show their own connections to self-rated health and the results are limited to the directionality and internal category.

\section{Conclusion}

Our findings are in line with previous research showing an association between work-family conflict and health. More frequent work-family conflict was associated with suboptimal self-rated health by all the work-family conflict indicators tested. We also found that educational level modified these associations, but only among women.

Future research should incorporate the role of cultural differences around gender in a Brazilian context, to show how this affects family and work spheres for both genders. It is also necessary to understand the effect of decision latitude, social support and other relevant moderating effects on the relationship between work-family conflicts and health, according to socioeconomic position and job occupation, and across gender groups. We believe that the opportunity for personal development for both genders and enrichment of everyday family life will be guaranteed by higher gender equality in taking care of home duties and looking after children. This change might decrease stress levels and positively influence priorities for women and men in the use of time for themselves, improving health and well-being. This is especially important in countries like Brazil, where large gender inequalities interact with other social and economic inequalities. Handling the spillover between job and family demands in modern life, especially in big cities, is a great challenge and more than individual (or family) arrangements are necessary. Macrolevel and organizational policies are also necessary to promote changes in traditional patterns of behaviour and to foster gender equality and social justice.

Acknowledgments The authors thank the ELSA-Brasil participants who agreed to take part in this study. The ELSA-Brasil baseline study was supported by Brazil's Ministry of Health (Department of Science and Technology) and Ministry of Science and Technology (Study and Project Funding Agency-FINEP and National Research Council-CNPq) (grants $01060010.00 \mathrm{RS}, 01060212.00 \mathrm{BA}, 01060300.00 \mathrm{ES}, 0106$ 0278.00 MG, $01060115.00 \mathrm{SP}$, and $01060071.00 \mathrm{RJ})$. This work was conducted during a Joint Brazilian-Swedish Research Collaboration supported by the International Cooperation Program CAPES/STINT. Financed by CAPES - Brazilian Federal Agency for Support and Evaluation of Graduate Education within the Ministry of Education of Brazil. This paper was prepared while RG was a visiting researcher at CHESS (Forte 2014 2680). ST is a senior researcher at CHESS (Forte 2012-0615). RHG, DC and EMA are research fellows of the National Research Council (CNPq). The funding source had no influence over the study design, data collection, analysis and interpretation, writing the paper or the decision to publish.

Authors' Contributions RG participated in study design, statistical analysis and data interpretation and drafted the manuscript. LJ participated in statistical analysis and data interpretation of data. ST, CvD, LC and JG participated in data interpretation, contributed with intellectual content to the paper and final review of the paper. EMLAA and DC participated in study design, data interpretation and final review of the paper. All the authors have read and approved the final manuscript.

\section{Compliance with Ethical Standards}

Conflict of Interest The authors declare that they have no competing interests.

Informed Consent All procedures followed were in accordance with the ethical standards of the Helsinki Declaration of 1975, as revised in 2000. The study was approved by the National Research Ethics Commission (Comissão Nacional de Ética em Pesquisa, CONEP; No. 976/2006) and by all institutions involved in the study. Informed consent was obtained from all participants for being included in the study.

Open Access This article is distributed under the terms of the Creative Commons Attribution 4.0 International License (http:// creativecommons.org/licenses/by/4.0/), which permits unrestricted use, distribution, and reproduction in any medium, provided you give appropriate credit to the original author(s) and the source, provide a link to the Creative Commons license, and indicate if changes were made. 


\section{References}

1. Bianchi SM et al. Is anyone doing the housework? Trends in the gender division of household labor. Soc Forces. 2000;79(1):191-228.

2. Geurts SA, Demerouti E. Work/non-work interface: a review of theories and findings. Handbook Work Health Psychol. 2003;2: 279-312.

3. Agénor, P.-R, Canuto O. Gender equality and economic growth in Brazil. 2013

4. Gaddis I, Pieters J. Trade liberalization and female labor force participation: evidence from Brazil. 2012.

5. Berntsson L, Lundberg U, Krantz G. Gender differences in workhome interplay and symptom perception among Swedish whitecollar employees. J Epidemiol Community Health. 2006;60(12): 1070-6.

6. Roeters A. Cross-national differences in the association between parental work hours and time with children in Europe: a multilevel analysis. Soc Indic Res. 2013;110(2):637-58.

7. Sweden S. Women and men in Sweden: facts and figures 2014. 2014.

8. Bruschini MCA. Trabalho e gênero no Brasil nos últimos dez anos. [Work and gender in Brazil in the last ten years]. Cad Pesqui. 2007;37(132):537-72.

9. de Santana Pinho P, Silva EB. Domestic relations in Brazil: legacies and horizons. Lat Am Res Rev. 2010;45(2):90-113.

10. da Costa Fernandes J et al. Jornada de trabalho e comportamentos de saude entre enfermeiros de hospitais publicos [Working hours and health behaviour among nurses at public hospitals]. Rev Latinoam Enfermagem. 2013;21(5):1104-11.

11. Rotenberg L, Silva-Costa A, Griep RH. Mental health and poor recovery in female nursing workers: a contribution to the study of gender inequities. Rev Panam Salud Pública. 2014;35(3):179-85.

12. Greenhaus JH, Beutell NJ. Sources of conflict between work and family roles. Acad Manag Rev. 1985;10(1):76-88.

13. Bell AS, Rajendran D, Theiler S. Job stress, wellbeing, work-life balance and work-life conflict among Australian academics. Sensoria: J Mind Brain Cult. 2012;8(1):25-37.

14. Hobson B. Work-life balance: the agency and capabilities gap. Oxford: Oxford University Press; 2013.

15. Huffman AH et al. The importance of construct breadth when examining interrole conflict. Educ Psychol Meas. 2008;68(3):515-30.

16. Frone MR, Russell M, Cooper ML. Relation of work-family conflict to health outcomes: a four-year longitudinal study of employed parents. J Occup Organ Psychol. 1997;70(4):325-35.

17. Carlson DS, Kacmar KM, Williams LJ. Construction and initial validation of a multidimensional measure of work-family conflict. J Vocat Behav. 2000;56(2):249-76.

18. Bianchi SM, Milkie MA. Work and family research in the first decade of the 21st century. J Marriage Fam. 2010;72(3):705-25.

19. Eby LT et al. Work and family research in IO/OB: content analysis and review of the literature (1980-2002). J Vocat Behav. 2005;66(1):124-97.

20. Michel JS et al. A comparative test of work-family conflict models and critical examination of work-family linkages. J Vocat Behav. 2009;74(2):199-218.

21. Nohe $\mathrm{C}$ et al. The chicken or the egg? A meta-analysis of panel studies of the relationship between work-family conflict and strain. 2014.

22. Lallukka T et al. Work-family conflicts and subsequent sleep medication among women and men: a longitudinal registry linkage study. Soc Sci Med. 2013;79:66-75.

23. Schieman S, Glavin P. Education and work-family conflict: explanations, contingencies and mental health consequences. Soc Forces. 2011;89(4):1341-62.
24. Byron K. A meta-analytic review of work-family conflict and its antecedents. J Vocat Behav. 2005;67(2):169-98.

25. Frone MR, Russell M, Cooper ML. Antecedents and outcomes of work-family conflict: testing a model of the work-family interface. J Appl Psychol. 1992;77(1):65.

26. Kinnunen $U$ et al. Interface between work and family: a longitudinal individual and crossover perspective. J Occup Organ Psychol. 2010;83(1):119-37.

27. Kinnunen U, Geurts S, Mauno S. Work-to-family conflict and its relationship with satisfaction and well-being: a one-year longitudinal study on gender differences. Work Stress. 2004;18(1):1-22.

28. Christiaens W, Bracke P. Work-family conflict, health services and medication use among dual-income couples in Europe. Sociol Health Illn. 2014;36(3):319-37.

29. Mi-Hye C. Gender, leisure and time constraint: employed men and women's experience. Dev Soc. 2006;35(1):83-105.

30. Krantz G, Berntsson L, Lundberg U. Total workload, work stress and perceived symptoms in Swedish male and female white-collar employees. Eur J Public Health. 2005;15(2):209-14.

31. Hämmig O, Bauer G. Work-life imbalance and mental health among male and female employees in Switzerland. Int J Public Health. 2009;54(2):88-95.

32. Lunau T et al. A balancing act? Work-life balance, health and wellbeing in European welfare states. Eur J Public Health. 2014;24(3): $422-7$.

33. Ludermir $\mathrm{AB}$, Lewis $\mathrm{G}$. Is there a gender difference on the association between informal work and common mental disorders? Soc Psychiatry Psychiatr Epidemiol. 2005;40(8):622-7.

34. Winter $\mathrm{T}$ et al. Work-family conflicts and self-rated health among middle-aged municipal employees in Finland. Int J Behav Med. 2006;13(4):276-85

35. Cullati S. The influence of work-family conflict trajectories on selfrated health trajectories in Switzerland: a life course approach. Soc Sci Med. 2014;113:23-33.

36. Leineweber $\mathrm{C}$ et al. Work-family conflict and health in Swedish working women and men: a 2 -year prospective analysis (the SLOSH study). Eur J Public Health. 2013;23(4):710-6.

37. Bailis DS, Segall A, Chipperfield JG. Two views of self-rated general health status. Soc Sci Med. 2003;56(2):203-17.

38. Kaplan G, Baron-Epel O. What lies behind the subjective evaluation of health status? Soc Sci Med. 2003;56(8):1669-76.

39. Mavaddat $\mathrm{N}$ et al. Relationship of self-rated health with fatal and non-fatal outcomes in cardiovascular disease: a systematic review and meta-analysis. PLoS One. 2014;9(7), e103509.

40. Nordenmark M. Balancing work and family demands do increasing demands increase strain? A longitudinal study. Scand J Public Health. 2004;32(6):450-5.

41. Eek F, Axmon A. Gender inequality at home is associated with poorer health for women. Scand J Public Health, 2014: p. 1403494814562598.

42. Schieman S, Whitestone YK, Van Gundy K. The nature of work and the stress of higher status. J Health Soc Behav. 2006;47(3):24257.

43. Erikson R, Torssander J. Clerics die, doctors survive: a note on death risks among highly educated professionals. Scand J Public Health. 2009;37(3):227-31.

44. Höfelmann DA, Garcia LP, de Freitas LRS. Self-rated health in Brazilian adults and elderly: data from the National Household Sample Survey 2008. Salud Publica Mex. 2014;56(6):603-11.

45. Aquino EM et al. Brazilian longitudinal study of adult health (ELSA-Brasil): objectives and design. Am J Epidemiol. 2012;175(4):315-24.

46. Chor D et al. Questionnaire development in ELSA-Brasil: challenges of a multidimensional instrument. Rev Saude Publica. 2013;47:27-36. 
47. Schmidt MI et al. Strategies and development of quality assurance and control in the ELSA-Brasil. Rev Saude Publica. 2013;47:10512 .

48. Pinto KA. Gênero e conflito entre trabalho e família: relacao com a saúde física e mental de adultos no Brasil [Gender and work-family conflict: relationship with physical and mental health of adults in Brazil]. Ph.D Thesis. Bahia, Brazil: Federal University of Bahia; 2013.

49. Fox J, Monette G. Generalized collinearity diagnostics. J Am Stat Assoc. 1992;87(417):178-83.

50. Hosmer DW, Lemeshow S. Introduction to the logistic regression model. Applied Logistic Regression, Second Edition, 2000: p. 130.

51. Rotenberg $\mathrm{L}$ et al. Housework and recovery from work among nursing teams: a gender perspective. New Solutions: J Environ Occup Health Policy. 2010;20(4):497-510.

52. Nordenmark M, Vinberg S, Strandh M. Job control and demands, work-life balance and wellbeing among self-employed men and women in Europe. Vulnerable Groups Inclusion. 2012;3.

53. Boye K. Happy hour? Studies on well-being and time spent on paid and unpaid work. 2008.
54. Amstad FT et al. A meta-analysis of work-family conflict and various outcomes with a special emphasis on cross-domain versus matchingdomain relations. J Occup Health Psychol. 2011;16(2):151.

55. Jylhä M. What is self-rated health and why does it predict mortality? Towards a unified conceptual model. Soc Sci Med. 2009;69(3): 307-16.

56. McEwen BS, Seeman T. Protective and damaging effects of mediators of stress: elaborating and testing the concepts of allostasis and allostatic load. Ann N Y Acad Sci. 1999;896(1):30-47.

57. Araújo ER. Technology, gender and time: a contribution to the debate. Gender Work Organ. 2008;15(5):477-503.

58. Lewis S, Gambles R, Rapoport R. The constraints of a 'work-life balance' approach: an international perspective. Int J Human Resour Manag. 2007;18(3):360-73.

59. Menzies H, Newson J. Time, stress and intellectual engagement in academic work: exploring gender difference. Gender Work Organ. 2008;15(5):504-22.

60. Billing TK et al. Work-family conflict and organisationally valued outcomes: the moderating role of decision latitude in five national contexts. Appl Psychol. 2014;63(1):62-95. 